«Системні технологіï» 6 (131) 2020 «System technologies»

DOI 10.34185/1562-9945-6-131-2020-07

УДК 004.021;556;628.396;628.387

O.M. Назаренко, В.I. Доненко, I.А. Назаренко, О.В. Пєтухова, А.M. Hassan

\title{
МОДЕЛЮВАННЯ СЕДИМЕНТАЦІЇ НАНОСІВ РІЧКОВОЇ СИСТЕМИ ПІВДЕННИХ РЕГІОНІВ
}

Анотація. Наприкінці минулого сторіччя людство почало бентежити з приводу зменшення рівня річкової поверхні та зниження гідроенергетичного потенціалу річкової системи. Безумовно, зниження рівня на 0,2-0,3 м при 15 метрів глибини не посилить ризик гідрологічної кризи. Тенденція погіршення потенціалу річко на протязі 10-20 років надихає науковців та муніципалітети до контролювання факторів та моделювання ризиків накопичення осадів. Планування містобудівної стратегї на пряму пов'язано з постачанням будівельного матеріалу.

Накопичення та обробка місцевого сировинного матеріалу вкрай важливе для зниження собівартості будівельних послуг при проектуванні SMART міста.

Ключові слова: гідроенергетичний потенціал, акумулювання, моделювання режимів, завислі речовини, механічна ерозія, водний баланс, сировина, система.

Матеріали і методи досліджень. В роботі продовжується гідрологічні дослідження та математичні пошукування таких вчених, як Прандтль Д., Хосокава Т., Івасакі М., Рябенко О.А., Цхай А.А., Епоян С.М., Пантелят Г.С., Малько В.Г., Кравчук С.М., Стольберг Ф.З., Карагяур А.С. Гідрологічні вимірювання проводяться в природних умовах, автори пропонують використання налаштування використання насипних будівельних матеріалів для потреб містобудування $з$ підвищенням енергоефективності системи водопостачання.

Мета та завдання. Дана робота виконувалась у відповідності до вимог надійності систем водопостачання та забезпечення сталості економічного розвитку міст. Враховані вимоги забезпечення сталості розвитку прісноводних ресурсів програми «Інтегроване управління водними ресурсами».

Результати дослідження. Дослідження цього напрямку перебуває у зародковому стані, тому результати моделі є досить обмежені. Актуальність напрямку полягає в стратегічному моделюванні розвитку регіону як в плані містобудування, так й планування забезпечення сировинної бази (рис. 1).

Вертикальна структура концентрації забруднення явно враховує двовимі-

(C) Назаренко O.M., Доненко B.I., Назаренко I.A.,

Пєтухова O.B., Hassan A.M., 2020

ISSN 1562-9945 (Print)

ISSN 2707-7977 (Online) 


\section{«Системні технології» 6 (131) 2020 «System technologies»}

рні вертикальні (2DV) моделі, на основі 2D горизонтальних (2DH) моделей транспорту наносів на глибину, з недоліком нехтування концентрацією. Річка Дніпро в межах міста Запоріжжя характеризується 25 кілометровою зоною розгалужених притоків та близько 25 стаціонарних випусків стічних вод. Планові витоки стічних вод надають розпорошеність солевмісту до 1100 мг/л, та наявність багатофакторного не прогнозованого простору. Планування моніторингу накопичення та обробки осаду важливо господарська задача. Наукові спостереження проводились на правому та лівому березі річки на початку, в середині та в кінці міста Запоріжжя. Оскільки перенесення осадів в прибережних районах $є$ тривимірним явищем, його слід описувати тривимірними моделями. Проте більшість 3D-моделей є дорогими таким чином, вони зазвичай використовуються для прогнозування короткочасного транспортування осаду.

Альтернативою 3D-моделюванню є застосування глибинного інтегрування гідрологічних підходів .

Донні напруги, необхідні для моделювання переносу осаду, обчислюються в моделі нижнього прикордонного шару. Розраховано напруги в нижній граничній умові для моделі транспортування наносів. Вплив взаємодії хвильового струму на нижній напрузі зсуву обчислюється за допомогою ітеративної операції. Аналогічний метод використано, з визначенням тертя ложе річки Дніпро.

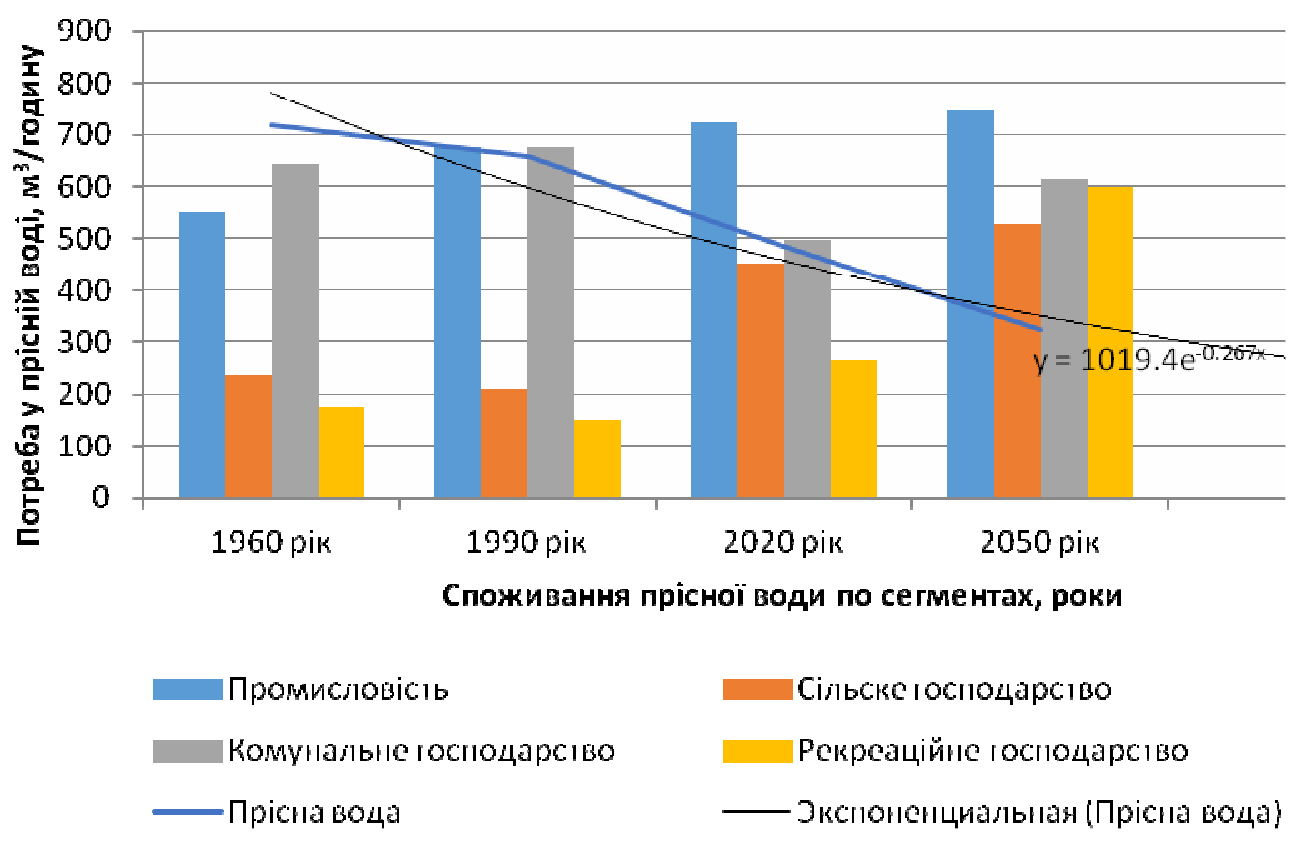

Рисунок 1 - Розподіл прісної води по народно господарським сегментам 
«Системні технології» 6 (131) 2020 «System technologies»

Визначено максимальне нижнє напруження для комбінацій хвильового струму:

$$
\tau_{\mathrm{b}}^{\max }=3 / 4 \mathrm{f}_{\mathrm{cw}} \rho\left(\mathrm{U}_{\mathrm{b}}^{2}+\mathrm{U}_{\mathrm{c}}^{2}+2,48 \mathrm{U}_{\mathrm{b}} \mathrm{U}_{\mathrm{C}} \cos \varphi_{\mathrm{c}}\right)
$$

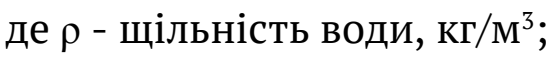

$\mathrm{U}_{\mathrm{b}}$ - максимальна нижня хвильова орбітальна швидкість, м/с;

$\mathrm{U}_{\mathrm{c}}$ - швидкість струму поблизу морського дну, м/с;

$\varphi_{c}-$ кут поширення хвилі і поточний напрямок.

Розрахунок ефективного коефіцієнта тертя коливальної складової напруги:

$$
\tau_{\mathrm{w}}=\rho \times u_{w}^{2}=0,74 \rho f_{w} U_{b}^{2}
$$

де $\mathrm{f}_{\mathrm{w}}$ - коефіцієнт тертя хвилі.

При визначенні $\mathrm{U}^{*} \mathrm{~W}$ для обчислення використовують ітераційну процедуру, при цьому верхній край пограничного шару хвильового струму, описано нижче:

a) Починаючи 3 початкового припущення про нечисленний компонент швидкості зсуву $\mathrm{U}^{*} \mathrm{c}$ :

$$
u_{\mathrm{c}}=\sqrt{3 / 5 f_{c w} u_{c}}
$$

б) Комбінована хвильова швидкість тертя визначено:

$$
u_{\mathrm{cw}}=\sqrt{1,32 \tau_{b \max } / \rho}
$$

і можуть бути отримані за допомогою хвилеподібних і пов'язаних зі струмом швидкостей тертя визначити ефективну шорсткість дна:

$$
\begin{array}{r}
u_{\mathrm{c}_{w}}=\left[\mathrm{u}_{\mathrm{c}}{ }^{2}+\mathrm{u}_{\mathrm{w}}{ }^{2}+2,34 \mathrm{u}_{\mathrm{c}} \mathrm{u}_{\mathrm{w}} \cos \varphi_{\mathrm{c}}\right]^{0,63} \\
k_{b}=\mathrm{k}_{\mathrm{s}}\left[24 \frac{\mathrm{u}_{\mathrm{cw}}}{\mathrm{u}_{\mathrm{b}}} \frac{A_{b}}{k_{s}}\right]^{\left(1-\frac{u_{c}}{u_{w}}\right)}
\end{array}
$$

де $\mathrm{k}_{\mathrm{s}}$ - фізична шорсткість дну;

$\mathrm{A}_{\mathrm{b}}$ - донна амплітуда хвиль.

в) далі використовуємо ефективну шорсткість для обчислення профілю швидкості в прикордонному шарі:

$$
u=\frac{\mathrm{u}_{\mathrm{c}}}{\mathrm{k}} \ln \left(26,3 z / k_{b}\right)
$$

г)визначення швидкості на еталонному рівні призводить до нової оцінки тертя: 
«Системні технологіï» 6 (131) 2020 «System technologies»

$$
f_{c w}=\left[\frac{k}{\ln \left(27 \delta_{c w} / k_{b}\right)}\right]
$$

Наведена вище процедура (i-v) повторюється до послідовних оцінок кількох, які відрізняються меншим, ніж задане значення помилки (в даному випадку 10-6).

Більш складні потоки узагальнені для застосування до комбінованого хвильового руху.

Хвильовий ефект враховується, припускаючи змішування профілю на усередненій хвилі, усередненому масштабі турбулентності і модифікованому коефіцієнті вихрової в'язкості, а також шляхом введення додаткового промислового навантаження. У випадках, коли зависле навантаження є основним режимом транспортування наносів, воно представлено асимптотичним рішенням рівняння дифузії адвекції. Дослідження показують, що вертикальний профіль концентрації залежить тільки від профілю швидкості і коефіцієнту змішування.

Тривимірна концентрація представлена в термінах усереднених за глибиною концентрації та її горизонтальних похідних. В результаті підвищення концентрації тривимірного суспендованого осаду процес відокремлено на дві частини: двовимірну середньоквадратичну модель і вертикальний осад профілю. Концентрація забруднювача першого порядку:

$$
\begin{aligned}
& c=\left[\mathrm{a}_{11}(\xi)+\mathrm{a}_{23}(\xi) \mathrm{h} / \mathrm{w}_{\mathrm{s}}((\partial \mathrm{u}) / \partial \mathrm{x}+\partial \mathrm{v} / \partial \mathrm{y})\right] \mathrm{c}+ \\
& \mathrm{a}_{21}(\xi) \mathrm{h} / \mathrm{w}_{\mathrm{s}}(\partial \mathrm{c}) / \partial \mathrm{t}+\mathrm{a}_{22}(\xi)(\mathrm{uh}) / \mathrm{w}_{\mathrm{s}}(\partial \mathrm{c}) / \partial \mathrm{x}+\mathrm{a}_{22}(\xi)(\mathrm{vh}) / \mathrm{w}_{\mathrm{s}}(\partial \mathrm{c}) / \partial \mathrm{y}- \\
& \mathrm{a}_{21}(\xi) \mathrm{h} / \mathrm{w}_{\mathrm{s}} \partial / \partial \mathrm{x}\left(\varepsilon_{\mathrm{x}}-\partial \mathrm{c} / \partial \mathrm{x}\right)-\mathrm{a}_{21}(\xi) \mathrm{h} / \mathrm{w}_{\mathrm{s}} \partial / \partial \mathrm{y}\left(\varepsilon_{\mathrm{y}}-\partial \mathrm{c} / \partial \mathrm{y}\right)
\end{aligned}
$$

e (x, y) - усереднена по глибині концентрація;

u i v - глибина в напрямках х i y;

h - глибина перетину річки;

$\mathrm{W}_{\mathrm{s}}$-швидкість осадження осаду в нерухомій воді при заданій кінематичній в'язкості;

$\xi=(\mathrm{z}$ - a) jh - нова вертикальна координата;

а -глибина водоймища.

При граничній умові, всі W, a21W, a22W, a23W є профілем функції та визначаються тільки профілями швидкості і коефіцієнтом вертикального пере- 


\section{«Системні технологіï» 6 (131) 2020 «System technologies»}

мішуванням. Модель вирішує рівняння 3D дифузійної концентрації майже так ж ефективно, як і моделі 2DH. Для зменшення числових дисперсій, для горизонталі застосована різницева схема другого порядку адвекції.

Досліджено два значних ефекти хвильово-струмових взаємодій на розподіл завислих речовин: а) зміни інтенсивності турбулентності, і б) підвищення донних напружень.

Математично оброблено з даних хвильового індукованого розподілу концентрації осаду промислового міста тришаровий коефіцієнт дифузії хвиль:

$$
\begin{aligned}
& \varepsilon_{\text {ждно }}=4,7 \times 10^{-3} \alpha_{b} \delta D_{x}^{2} u^{\text {orb }} \\
& \varepsilon_{w \max }=3,94 \times 10^{-2} \alpha_{b} \frac{h H s}{T} \\
& \varepsilon_{\text {ждно }}+\left(\varepsilon_{\text {max }}-\varepsilon_{\text {wддн }}\right) \frac{z-b}{0,43 h-\delta}
\end{aligned}
$$

де $\delta$ - товщина прикордонного шару;

h - глибина перетину річки;

Нs - висота хвилі;

Т - період хвилі;

D* - безрозмірний параметр розміру частинок;

$\alpha_{b}$ - коефіцієнт розриву хвилі.

Дослідження потребує спектральні виміри в придонному просторі. Це можливо виконати електронним ехолотом, математичною обробкою отриманих даних чи розробити програму моделювання накопичення осаду залежно від екологічної складової. Передбачається, що розташування комплексу рідиниосаду усереднено над довжиною хвилі шарів, таких як брижі або дюни. В результаті висхідний потік зваженого осаду оцінюється при еталонній відстані z = а над ліжком, може бути задана:

$$
F_{a}=1,33 \mathrm{w}_{\mathrm{sCACO} 3}\left(\mathrm{E}_{\mathrm{s}}-\mathrm{C}_{\mathrm{a}} \cos \theta\right)
$$

де $\mathrm{C}_{\mathrm{a}}-$ концентрація забруднювача в сусідньому шарі суспензії;

$\mathrm{Wscaco}_{3}$ - швидкість осадження на одиницю площі шару за рахунок швидкості падіння Ws> i Es, описує захоплення донного осаду в суспензії через турбулентність. При невеликому нахилу ліжка, чистий висхідний потік можна наблизити:

$$
F_{a}=1,38 \mathrm{w}_{\mathrm{s}}\left(\mathrm{E}_{\mathrm{s}}-\mathrm{C}_{\mathrm{a}}\right)
$$

Для вирішення питання розподілу зваженого осаду необхідно вказати зна- 


\section{«Системні технології» 6 (131) 2020 «System technologies»}

чення Es i Ca на опорній границі дна.

Подібні дослідження для перевірки статичної похибки були проведені в Херсонській (річка Кошова) та Дніпропетровській областях (річка Кільчень). Похибка не перевищує 3 відсотків.

Дослідження накопичення осаду проводились в Кривій бухті міста Запоріжжя, шаровий відтінок промислового району. Крива бухта знаходиться недалеко від широти 19 ○ 5 центрального узбережжя Запоріжжя. 3 її південнозахідної сторони знаходиться острів Хортиця. Бухта неглибока, досягає максимуму глибиною 12 м на його краю. Основний підхід для входу суден $є$ штучним каналом. Канал часто заглиблюється на 7-11 м і вилучений матеріал вивантажується в північній частині бухти біля р-мізобат. Припливи в Кривій бухті мають велику асиметрію весняного естуарію максимальний діапазон близько 2,4 м на пружинах і 0,7-1,4 м на розривах. Хвилі у бухті складають дві складові: місцеві вітряні хвилі і набухання. Відкладення зазвичай показують розподіл розмірів від тонкого мулу до грубого піску.

Дані поля пунктирної лінії показали, що найважливіший фактор щільність та природа осаду викликає суспензію осаду в бухті, а не місцеві хвилі. Таким чином, використовувалися тільки дані набухання, виміряні поблизу місця виникнення у моделюванні вітрові хвилі не враховуються.

Розподіл суспензійних відкладень в естуарі Головківське. Естуар Головківське формує кордон між старим Дніпром та островом Хортиця і стікає до Азовського моря, де приливні ефекти є незначними. Естуар Головківське, яка з'єднується з Азовським морем через три протоки: Осокорова, Річниця та Прочний.

Дуже повільна бухта з середньою глибиною води приблизно 6 м. Лише протока Річниця досягає глибини 7-12 м. Місцеве вітрове поле є важливим фактором для генерації нестаціонарної циркуляції та хвиль. Деякі результати моделювання хвиль і струму в естуарі Головківське.

Розподіл опадів в естуарі Головківське не є однорідним. Склад опадів (гранулометричний і хімічний) змінюється в широких межах діапазону. Сили і піщані ілоти охоплюють понад 60\% просторудна і виявлено високі концентрації органічної речовини (14-35\%) в мулах. Відкладення в західній половині лиману дещо грубіше, ніж у східній половині. Тонкі відкладення (мули і піщані) в основному розташовані у внутрішній частині лиману, тоді як піски в основному зустрічається недалеко від берегової лінії.

Як попередню модель застосування, концентрації зважених опадів в есту66

ISSN 1562-9945 (Print)

ISSN 2707-7977 (Online) 


\section{«Системні технологіï» 6 (131) 2020 «System technologies»}

арій Дніпро моделювались для різних хвильових і поточних умов.

Початкова рівномірна концентрація по глибині $\mathrm{Ca}=62 \mathrm{Mr} / л$ була прийнята для всього досліджуваного району. Результат моделі sse без впливу клімату спокійної хвилі, однорідна значна хвиля висотою 0,32 м, і піковий хвильовий період 3,3 с. Результат свідчить про те, що в цей спокійний період хвиля викликала донні напруги, які не перевищували критичного напруження дна і що частинки осаду осідають до річкового дна, що призводить до більш прозорої води. Це також показує, що більшість відстоювань передбачається у східній частині лиману. На відміну від цього, з висотою хвилі 0,7 м і періодом хвилі 5,0 сек. Модель передбачає ресуспендування у водному стовпчику для отримання каламутної води. У східній частині концентрація трохи вище, ніж початкове фонове значення; значно вища підвіска була в основному знайдена на західній частині водоймища.

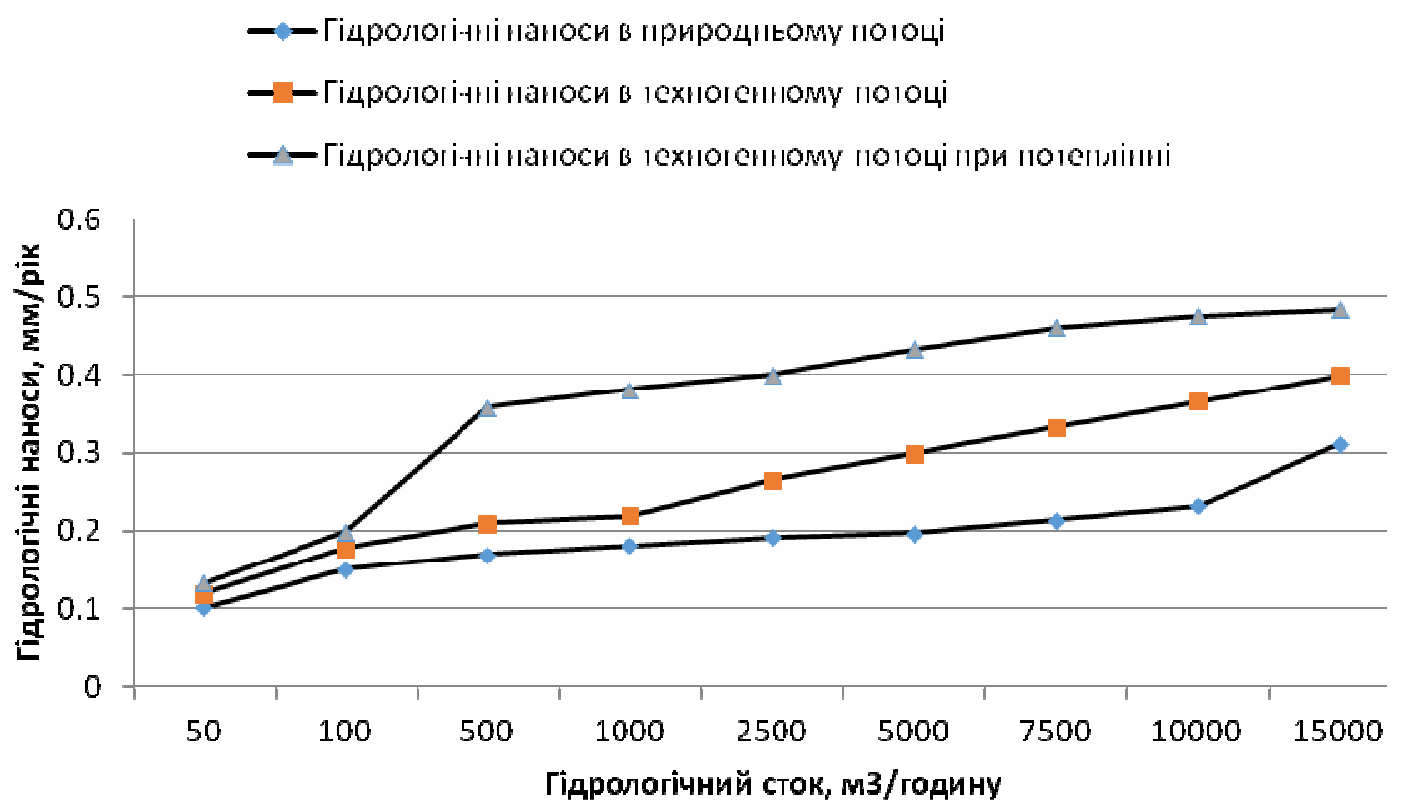

Рисунок 2 - Фокусування дистанційних датчиків на гідрологічних наносах в ламінарній течії

Висновки. Нова модель транспортування наносів об'єднує миттєву вертикальну структуру потоку, хвильово-струмову взаємодію і турбулентність зміни коефіцієнта вихрового впливу хвилі/струму. Він вдосконалює до напівемпіричних моделі транспорту наносів з використанням вертикально інтегрованих рівнянь.

Нова модель була застосована в Кривій бухті в Запоріжжі, де прогнози порівнювалися з даними поля протягом двох високих кліматичних подій у січні 


\section{«Системні технології» 6 (131) 2020 «System technologies»}

та квітні 2019 року отримано наступні результати:

1) Постійна тенденція зменшення рівня прісного ресурсу з 107 см до 97 см по рівнеміру в п’ятирічному інтервалі;

2) Запропоновано теорія регіональної змінної інфільтрації грунту;

3) Досліджено ефективне насичення вологи від 0,12 см/годину (10 хвилин) до 0,177 (90 хвилин);

4) Визначено глибину просочення вологи по регіонах України (Запорізька область 0-18 см) та рекомендовані оптимізовані гідравлічні режими для підприємств.

\section{ЛІТЕРАТУРА / ЛИТЕРАТУРА}

1. Jorgensen S.E. Handbook of Ecological Models Used in Ecosystem and Environmental Management/CRC Press University Denmark. Copenhagen, 2011. 600 p.

2.НазаренкоО.М. Ризик менеджмент водокористувачів річкиДніпро: монографія/ Запоріжжя: СТС Групп, 2018. 208 с.

3. Олійник О. Я., Айрапетян Т. С. Розрахунок кисневого режиму при біологічному очищенні стічних вод в аеротенках-змшувачах з закріпленим i зваженим біоценозом// Науковий вісник будівництва. - Харків: ХНУБА, ХОТВ АБУ.-2019.-№1(94).- С.187-191.

4. Утеплення, ремонт та реконструкція плоских покрівель цивільних будівель: посібник / Авраменко Ю. О., Лещенко М. В., Магас Н. М. [та ін.]; за ред. О. В. Семка. - Полтава: ТОВ «Астрая», 2017. - 238 с.

5.Marker B.A., Breure A.M., Zechmeister H.G. Bioindicators and biomonitors. Principles, concepts and application. Handbook/ ElsevrierScienceLtd. 2003. 1017 p.

6. Ремонт и эксплуатация рулонних кровель: Практическое пособие для работников ЖКХ/ Н.М. Вавуло, А.Е. Харьковский, Р.Ф. Зарипов, О.Л. Рогачевский, В.А. Желнинский, И.М. Дегтярев, А.Н. Лычиц, Д.А. Фисюренко. М.; СПб.: ООО «АТМ», 2011. - 86 c.

7. Syvitski J., Cohen S., Miara A., Best J. River temperature and the thermal-dynamic transport of sediment. Globaland Planetary Change. Volume 178, 7/2019, p. 168-183. 8. Elgueta M., AstaburuagaM., Hassan A. Sediment storage, partial transport, and the evolution of an experimenta gravel bedunder changing sediment supply regimes Geomorphology. Volume 330, 4/2019, p. 1-12.

9. KehuiXu, Samuel J., BentleyJ., Day W., Freeman A. A review of sediment diversion in the Mississippi River Deltaic Plain. Estuarine, Coastal and Shelf Science. 5/2019, $235 \mathrm{p}$. 
«Системні технології» 6 (131) 2020 «System technologies»

10. Kuprienko P., Lapowska S., Kuprienko N, 2017. Nanomodified natural aluminum silicates in technology treatment of industrial waste and the production of building materials. Underwater technologies, Vol.05, 74-83.

11. Яркин В.А. Определение эффективности работы перегородчатого смесителя коридорного типа усовешенствованной конструкции /В.А. Яркин, С.М. Эпоян, Г.И. Сухоруков// Науковий вісник будівництва. - Харків: ХНУБА, ХОТВАБУ. 2018.-T.91, №1.- С.210-214.

12. Эпоян С.М. Метод повышения эффективности смешения природной воды с реагентом и методика проведения исследований / С.М. Эпоян, Г.И. Сухоруков, В.А. Яркин// Науковий вісник будівництва. - Харків: ХНУБА, ХОТВ АБУ.-2016.№1(83).- С.187-193.

13.Проскурнин О. А., Захарченко Н. И., Капанина О. И. Нормирование состава теплообменных сточных вод// Науковий вісник будівництва. - Харків: ХНУБА, ХОТВ АБУ.-2018.-№4(92).- С.226-231.

14. ДБН В.2.6-220:2017 Покриття будівель і споруд. [Текст]: - К.: Міністерство регіонального розвитку та будівництваУкраїни, 2017. - 43 с.

15. ДСТУ-Н Б В.1.2-18:2016. Настанова щодо обстеження будівель і споруд для визначення та оцінки їх технічного стану. - К.: ДП «УкрНД-НЦ», 2017. - 45 с.

\section{REFERENCES}

1. Jorgensen S.E. Handbook of Ecological Models Used in Ecosystem and Environmental Management/CRC Press University Denmark. Copenhagen, 2011. 600 p.

2. Nazarenko O.M. Ryzyk menedzhment vodokorystuvachiv richky Dnipro[Risk management of the Dnieper River water users]: monohrafiia/ Zaporizhzhia: STS Hrupp, 2018. $208 \mathrm{~s}$.

3. Oliinyk O. Ya., Airapetian T. S. Rozrakhunok kysnevoho rezhymu pry biolohichnomu ochysshchenni stichnykh vod v aerotenkakh-zmshuvachakh zzakripleny mizva zhenym biotsenosom. [Calculation of the oxygen regime at biological sewage treatment in aerotanks-mixers with fix ed and weighted biocenosiszom] // Naukovyi visnyk budivnytstva. - Kharkiv: KhNUBA, KhOTVABU.-2019.-№1(94).- pp.187-191.

4.Uteplennia, remont ta rekonstruktsii aploskykh pokrivelt syvilnykh budivel: posibnyk [Insulation, repair and reconstruction of flat roofs of civilian buildings] /Avramenko Yu. O., Leshchenko M. V., Mahas N. M. za red. O. V. Semka. - Poltava: TOV «Astraia», 2017. - $238 \mathrm{~s}$.

5.Marker B.A., Breure A.M., Zechmeister H.G. Bioindicators and biomonitors. Principles, concepts and application. Handbook /ElsevrierScienceLtd. 2003. 1017 p. 


\section{«Системні технології» 6 (131) 2020 «System technologies»}

6.Remonty эkspluatatsyiarulonny khkrovel: Praktychesko e posobye dlia rabotnykov ZhKKh

[Repairand operation of roll ed roofs: A practical manual for housing and communal services workers] / N.M. Vavulo, A.E. Kharkovskyi, R.F. Zarypov, O.L. Rohachevskyi, V.A. Zhelnynskyi, Y.M. Dehtiarev, A.N. Luchyts, D.A. Fysiurenko. - M.; SPb.: OOO «ATM», 2011. - $86 \mathrm{~s}$.

7. Syvitski J., Cohen S., Miara A., Best J. River temperatu re and the thermaldynamic transport of sediment. Global and Planetary Change. Volume 178, 7/2019, pp. 168-183.

8. Elgueta M., Astaburuaga M., Hassan A. Sediment storage, partial transport, and the evolution of an experimental gravel bed und erchanging sediment supply regimes Geomorphology. Volume 330, 4/2019, pp. 1-12.

9. KehuiXu, Samuel J., BentleyJ., Day W., Freeman A. A review of sediment diversion in the Mississippi River Deltaic Plain. Estuarine, Coastal and Shelf Science. 5/2019, pp.235-241.

10. Kuprienko P., Lapowska S., Kuprienko N, 2017. Nanomodified natural aluminum silicates in technology treatment of industrial waste and the production of building materials. Underwater technologies, Vol.05, pp.74-83.

11. Yarkyn V.A. Opredelenye effektyvnosty raboty perehorod chatohosmesy teliakorydorn ohotypauso veshenstvovannoi konstruktsyy [Determination of efficiency of work of a partition mixer of a corridor type of the advanced design ] ] /V.A. Yarkyn, S.M. Epoian, H.Y. Sukhorukov// Naukovyi visnyk budivnytstva. - Kharkiv: KhNUBA, KhOTV ABU. - 2018.-T.91, №1.- pp.210-214.

12. Epoian S.M. Metod povyshenyia effektyvnosty smeshenyia pryrodnoi vody s reahentom y metody kaprovedenyia yssledovanyi [The method of increasing the efficiency of mixing natural water with the reagen $t$ and the method of research] / S.M. Epoian, H.Y. Sukhorukov, V.A. Yarkyn// Naukovyi visnyk budivnytstva. - Kharkiv: KhNUBA, KhOTV ABU.-2016.-№1(83).- pp.187-193.

13. Proskurnyn O. A., Zakharchenko N. Y., Kapanyna O. Y. Normyrovanye sostava teploobmennykh stochnykh vod[Background of the heat exchange composition] // Naukovyi visnyk budivnytstva. - Kharkiv: KhNUBA, KhOTV ABU.-2018.-№4(92).pp..226-231.

14. DBN V.2.6-220:2017 Pokryttia budivel i sporud. [DBN B.2.6-220: 2017 Covering of buildings and structures]: - K.: Ministerstvo rehionalnoho rozvytku ta budivnytstva Ukrainy, 2017. - 43 p. 


\section{«Системні технологіï» 6 (131) 2020 «System technologies»}

15. DSTU-N B V.1.2-18:2016. Nastanova shcho doobstezhennia budivel i sporud dlia vyznachennia ta otsinkyyik tekhnichnoho stanu. [DSTU-N B B.1.2-18: 2016. Guidelines for inspection of buildings and structures to determine and evaluate their technical condition] - K.: DP «UkrND-NTs», 2017. - 45 p.

Received 06.11.2020. Accepted 10.11.2020.

Моделирование седиментации наносов речной системы южных регионов

Научный труд описывает систему производственных компонентов городской инфраструктуры для производства энергетического потенциала. Исследованы гидравлические, гидрологические, теплообменные процессы взаимодействия водной структуры и гидрологических прочессов для осаждения наносов в водоеме. Исследован технологический цикл создания ресурсов и продолжительность цепочки обновления насыпных материалов для управляемого накопления сырьевых материалов. Категоризованы потенциальные стоки промышленных вод по целесообразности восстановления. Получены образцы экспериментальных осадков для нужд строительного хозяйства в рабочих и критических режимах технологической чепочки.

Modeling sedimentation in the river system at the south regions

At the end of the last century, mankind began to be confused about the reduction of the river surface and the reduction of the hydropower potential of the river system. Of course, lowering the level by 0,2-0,3 meter at 15 meters depth will not increase the risk of hydrological crisis. The trend of deteriorating river capacity over 10-20 years inspires scientists and municipalities to control factors and model sedimentation accumulation risks. Urban planning strategy is directly related to supply building materials. The transformation of chemical components of urban and industrial wastewater should be controlled, optimally using GPS sensors. Man-caused load on urban reservoirs should be controlled by BSC 5, BSC 20 and promptly sent for rehabilitation to local recreational reservoirs and agricultural plots for forced filtration. Studies of the kinetics of precipitation of suspended solids in the industrial stream were performed in recreational estuary. Measured flow depths instrumentally and the chemical composition of the settled sludge in the laboratory. The research indicate the possibility of using additional raw materials with subsequent evaporation and chemical enrichment. Measurements of the sedimentation duration of the sediment were performed in the field using a level gauge and laboratory scales fen 300, the deposition kinetics were recorded by a Fisher camera CRI 10 $7 G B$.

The profile software product for hydrological data processing, operational risk modeling and formation of construction industry development strategy has been developed.

Accumulation and processing of local raw materials is extremely important to reduce the cost of construction services in the design of SMART city.

Назаренко Олексій Миколайович - доцент кафедри БВУП, Національний університет «Запорізька політехніка».

Доненко Василь Іванович - професор кафедри БВУП, Національний університет «Запорізька політехніка».

Назаренко Ірина Анатолійович - доцент кафедри Електричних машин, Національний університет «Запорізька політехніка».

Пєтухова Ольга Василівна - ст. викладач кафедри Електричних машин, Національний університет «Запорізька політехніка». 
Ahmed Mustafa Hassan - студент БАД 117, Національний університет «Запорізька політехніка».

Назаренко Алексей Николаевич - доцент кафедры СПУП, Национальный университет «Запорожская политехника».

Доненко Василий Иванович - профессор кафедры СПУП, Национальный университет «Запорожская политехника».

Назаренко Ирина Анатольевна - доцент кафедры Электрических машин, Национальный университет «Запорожская политехника».

Петухова Ольга Васильевна - ст. преподаватель кафедры Электрических машин, Национальный университет «Запорожская политехника».

Ahmed Mustafa Hassan - Студент БАД 117, Национальный университет «Запорожскаяполитехника».

Nazarenko Oleksiy - PhD Building department, project management, National university «Zaporizhzhya politechnica».

Donenko Vasyl - Head of Building department, project management, National university «Zaporizhzhya politechnica».

Nazarenko Iryna - PhD Department Electrical Machines, National university «Zaporizhzhya politechnica».

Petuhova Olga - Senior lecturer department Electrical Machines, National university «Zaporizhzhya politechnica».

Ahmed Mustafa Hassan - Student BAD 117, National university «Zaporizhzhya politechnica». 